\title{
NGHIÊN CỨU PHÁT HIỆN, ĐÁNH GIÁ NHANH BIẾN ĐộNG BỀ MẶT PHỤC VỤ CẬP NHẬT CƠ SỞ DŨ LIỆU NỀn ĐỊA LÝ TỶ LẸ 1:10.000
}

\author{
PHẠM THỊ HỒNG LÊ $\hat{(1)}^{(1)}$ PHẠM NGỌC PHÁT ${ }^{(1)}$, \\ TRÀ̀N QUANG MINH(1), PHẠM NGỌC MINH ANH(2) \\ ${ }^{(1)}$ Cuc Đo đạc, Bản đồ và Thông tin địa lý Việt Nam \\ ${ }^{(2)}$ Đại học Kinh tế Quốc dân
}

\section{Tóm tắt:}

Bài báo trình bày kết quả nghiên cứu ứng dụng giải pháp phát hiện, đánh giá nhanh, có hiệu quả cao về mức độ, phạm vi biến động bề mặt hiện trạng phục vu công tác lập dự án thiết kế kỹ thuậtdụ toán cập nhật co sở dũ liệu sử dụng ảnh SPOT 6/7 và CSDL nền địa lý quốc gia năm 2009. Nhóm tác giả chuyển đổi dũ liệu nền địa lý định dạng vector về định dạng raster kết hợp phân loại, gộp nhóm, tiếp đến sủ dụng kỹ thuật phát hiện biến động (change detection) dựa vào kỹ thuật phân loại ảnh đa phổ để lập ma trận biến động. Quy trình phát hiện, đánh giá biến động đối tuợng địa lý thư nghiệm tại khu vưc xã Hung Tây, huyện Hung Nguyên, tỉnh Nghệ An.

\section{1. Đặt vấn đề}

Trong giai đoạn lập dự án và thiết kế phục vụ thành lập và cập nhật cơ sở dữ liệu nền địa lý nếu quá trình khảo sát biến động phụ thuộc hoàn toàn vào công tác ngoại nghiệp tại địa phương sẽ gây tốn kém thời gian và kinh phí. Ngược lại, nếu đánh giá biến động chỉ dựa vào các nguồn báo cáo nội nghiệp hoặc giải pháp không phù hợp thì khi dự án đi vào thi công có khả năng phát sinh khối lượng diện tích đo bù so với thiết kế. Giải pháp xác định biến động các đối tượng bề mặt dựa trên tư liệu ảnh mới và cơ sở dữ liệu địa lý thời kỳ trước trước và phương pháp xử lý viễn thám có thể giải quyết một phần các vấn đề nêu trên.

Trong thời gian tới, Cục Viễn thám Quốc gia sẽ cung cấp ảnh viễn thám độ phân giải cao SPOT 6/7. Với độ phân giải không gian đối với các kênh Panchromatic là $1,5 \mathrm{~m}$, tổ hợp màu 1,5 $\mathrm{m}$ (Bảng 1), các kênh đa phổ $8 \mathrm{~m}$, khi kết hợp có thể xử lý tăng cường lên $6 \mathrm{~m}$ (Atrium, 2013), ảnh viễn thám SPOT 6 đảm bảo độ chính xác cho xác định biến động và cập nhật thông tin hiện trạng bề mặt.
Bảng 1: Bảng thông số chính của thiết bị quang hoc

\begin{tabular}{|c|l|}
\hline $\begin{array}{c}\text { Hệ thống quang } \\
\text { học }\end{array}$ & $\begin{array}{l}\text { 2 ống kính thiên văn Korsch, } \\
\text { độ mở ống kính } 200 \mathrm{~mm}\end{array}$ \\
\hline Mảng điện tử & $\begin{array}{l}\text { PAN: } 28,000 \text { pixels } \\
\text { MS: 4 x 7000 pixels }\end{array}$ \\
\hline & $\begin{array}{l}\text { Panchromatic: } 0,450-0,745 \mu \mathrm{m} \\
\text { Blue: } 0,450-0,520 \mu \mathrm{m}\end{array}$ \\
Phân giải phổ & $\begin{array}{l}\text { Green: } 0,530-0,590 \mu \mathrm{m} \\
\text { Red: } 0,625-0,695 \mu \mathrm{m}\end{array}$ \\
& Near Infrared: $0,760-0,890 \mu \mathrm{m}$ \\
\hline Độ rộng dải quét & $60 \mathrm{~km}$ tại điểm thiên đế \\
\hline Số bits & 12 bits \\
\hline
\end{tabular}

Công tác đánh giá biến động sử dụng ảnh đa thời gian hoặc sử dụng ảnh kết hợp dữ liệu GIS đã được ứng dụng nhiều trên thế giới và Việt Nam (JES, 2014; Phan Kiều Diễm, 2013). Tuy nhiên, quy trình sử dụng cơ sở dữ liệu từ định dạng vector sang định dạng raster để so sánh biến động với ảnh SPOT chưa được nghiên cứu tại Việt Nam. Do đó, nghiên cứu này góp phần bổ sung thêm phương pháp mới vào đánh giá biến động.

\section{Mục tiêu và phương pháp nghiên cứu}


Mục tiêu nghiên cứu là đề xuất giải pháp phát hiện, đánh giá, xác định mức độ, phạm vi biến động các nhóm đối tượng địa lý và xây dựng quy trình phục vụ công tác lập dự án, lập thiết kế kỹ thuật - dự toán.

Tài liệu sử dụng trong nghiên cứu:

+ Sử dụng ảnh SPOT 6/7 tại thời điểm nghiên cứu.

+ Cơ sở dữ liệu nền địa lý quốc gia hiện có thời gian trước.

Nếu chồng xếp các nhóm dữ liệu của CSDL nền địa lý cũ lên trên nền bình đồ ảnh vệ tinh mới để rà soát, phát hiện các đối tượng địa lý bị biến động bằng trực quan và các thao tác thủ công sẽ mất rất nhiều thời gian, công sức, phụ thuộc vào năng lực, kinh nghiệm của các tác nghiệp viên nên khó đảm bảo nâng cao năng suất, hiệu quả công việc (Umut Gunes Sefercik, 2008)

Trước vấn đề thực tiễn như trên, nghiên cứu đề xuất giải pháp phát hiện mức độ, phạm vi biến động phù hợp với điều kiện dữ liệu hiện nay do không có tư liệu ảnh vệ tinh ở thời điểm trước và kết hợp kỹ thuật phân loại ảnh vệ tinh, kỹ thuật phân tích biến động, trong đó dữ liệu đầu vào là CSDL nền địa lý quốc gia hiện có và tư liệu ảnh vệ tinh ở thời điểm hiện thời.

3. Xây dựng quy trình phát hiện, đánh giá, xác định mức độ phạm vi biến động

Quy trình phát hiện, đánh giá, xác định mức độ phạm vi biến động được trình bày tại hình 1 dưới đây.

\section{Mô tả các bước chính quy trình:}

\section{Ranh giới khu vục nghiên cúu}

Là đường địa giới khu vực nghiên cứu. Dùng làm đường bao để cắt phần $\mathrm{CSDL}$ và ảnh $\mathrm{SPOT}$ 6/7 đa phổ.

\section{CSDL khu vực nghiên cúu}

Cở sở dữ liệu khu vực nghiên cứu định dạng mdb, các đối tượng địa lý phân theo các nhóm lớp theo các feature dataset sử dụng trong phần mềm ArcGIS.

Trong nghiên cứu này chủ yếu phục vụ cho công tác đánh giá biến động lập thiết kế tập trung vào một số nhóm lớp nên nhóm lớp địa hình, nhóm biên giới - địa giới, các đối tượng dạng điểm, text, label (Point, Anonation) không được xét đến.

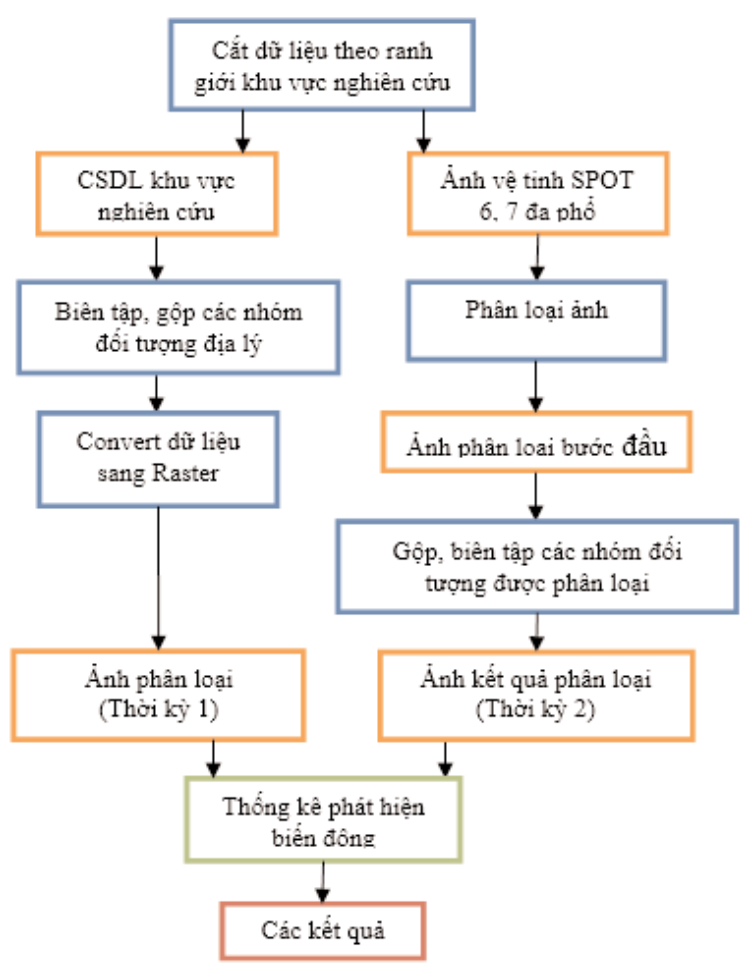

Hình 1: Qui trình phát hiện, đánh giá, xác định mức độ phạm vi biến động

\section{Biên tập gộp các nhóm đối tương}

Trước hết cần phải xây dựng các lớp phân loại. Các lớp phân loại cần được định rõ ràng về mặt chỉ tiêu. Các chỉ tiêu này được lựa chọn dựa vào đặc thù của tư liệu viễn thám đang sử dụng và tư liệu CSDL trong các nhóm đối tượng địa lý.

Có 7 lớp lựa chọn bao gồm:

- Dân cư (Nghĩa địa, khu dân cư,...)

- Đất trống (Đất trống, đường đất, cát, đồi trọc,...)

- Giao thông (Công trình giao thông, đường 
nhựa, đường bê tông,...)

- Khai thác (Khai thác, Công trình công nghiệp,...)

- Khu cây trồng nông nghiệp (Cây lúa, cây lương thực khác, cây rau, khu trồng cây nông nghiệp)

- Nước mặt (khu nuôi trồng thủy sản, ao, hồ, đầm, phá, sông suối, kênh, mương,...)

- Rừng (rừng cây bụi, rừng cây lá kim, cây lá rộng,...)

\section{Chuyển đổi dũ liệu sang dạng raster}

+ Trong ArcToolbox chọn công cụ Conversion Tools $=>$ To Raster $=>$ Feature to Raster để chuyển các đối tượng địa lý sang dạng raster.

+ Chọn độ kích thước pixel của file raster đầu ra là $6 \mathrm{~m}$ (tương ứng với kích thước pixel của bình đồ ảnh SPOT); Chọn định dạng file là GeoTIFF; Đặt tên file: gồm tên file gốc cộng thêm thành phần_MDB để dễ dàng phân biệt được đây là file ảnh của CSDL nền địa lý quốc gia tương ứng;

\section{Anh phân loại (thời kỳ 1)}

Sau bước 4 khi chuyển đổi từ dữ liệu vector sang dữ liệu raster ta được ảnh phân loại thời kỳ 1. Đặt tên file với phần mở rộng là _TK1

\section{Phân loại ảnh}

+ Tại những khu vực không có một thông tin nào về đối tượng cần phân loại sử dụng kỹ thuật phân loại không giám định. Phân loại không giám định chỉ sử dụng thuần túy thông tin ảnh. Trình tự xử lý có thể tóm tắt như sau:

- Các pixel trên ảnh đầu tiên được gộp thành nhóm có đặc trưng phổ tương đối đồng nhất bằng kỹ thật ghép lớp.

- Các nhóm lớp như vậy được sử dụng để tính các tham số thống kê cho quá trình phân loại tiếp theo.

- Việc xác định các tham số thống kê tệp mẫu phụ thuộc cụ thể vào các phương pháp phân loại sẽ được sử dụng. Tuy nhiên phần lớn các lớp thuật toán phân loại đều sử dụng các tham số như như giá trị trung bình tệp mẫu, ma trận, phương sai.

- Phân loại đa phổ để tách các thông tin cần thiết phục vụ cho việc theo dõi các đối tượng hay lập bản đồ chuyên đề là khâu then chốt của việc khai thác tư liệu viễn thám.

+ Sử dụng công cụ Unsupervised Classification trên phần mềm ERDAS hoặc phần mềm ENVI (Phân loại không giám định) để phân loại các nhóm đối tượng địa lý:

+ Ảnh vệ tinh được sử dụng là bình đồ ảnh đa phổ dạng số, gồm các kênh Red, Green, Blue và NIR;

+ Đặt tên các nhóm lớp đối tượng địa lý sẽ được phân loại theo tên các nhóm đối tượng địa lý của CSDL;

\section{Anh phân loại bước đầu}

Lựa chọn kênh phổ để tổng hợp màu là một công việc quan trọng quyết định chất lượng thông tin của kết quả tổng hợp màu.

Việc lựa chọn thông tin kênh phổ được xác định trên cơ sở sau:

- Đặc tính phản xạ phổ của các đối tượng cần giải đoán

- Nhiệm vụ giải đoán

- Yêu cầu đối với lực phân giải

- Đặc điểm của vùng cần tổng hợp màu...

Kết quả bước đầu của phân loại không giám định là file raster (kích thước pixel là $6 \mathrm{~m}$ ), trong đó nhóm pixel được thể hiện bằng các màu sắc khác nhau;

8. Gộp, biên tập các nhóm đối tượng được phân loại

Để chọn kênh phổ mang tính thông tin cao cần phân loại nhóm đối tượng chính cần giải đoán. Trên cơ sở các kênh phổ mang thông tin ta chọn ra kênh chính và kênh phụ để tổng hợp màu. 
+ Sử dụng bình đồ ảnh vệ tinh (ảnh màu tự nhiên, dạng số) để xem xét các nhóm pixel đã phân loại thuộc nhóm lớp nào để gán tên lớp đối tượng địa lý cho từng nhóm;

+ Có thể xuất hiện một số nhóm pixel có màu khác nhau nhưng bản chất chúng thuộc về cùng một lớp đối tượng địa lý thì phải tiến hành gộp lại (combine) thành một lớp duy nhất;

\section{Anh kết quả phân loại (Thời kỳ 2)}

+ Kết quả phân loại không giám định là file raster sau khi đã gộp được các nhóm pixel có các màu tương ứng với các nhóm đối tượng địa lý;

+ Tên file được lấy theo khu vực cộng thêm phần mở rộng_TK2 để dễ dàng phân biệt được đây là file ảnh phân loại của bình đồ ảnh;

10. Thống kê phát hiện biến động đối tương dịa lý (Change Detection Statistics)

+ Sử dụng công cụ Basic Tools $=>$ Change Detection $=>$ Change Dectection Statistics;

+ Với Initial State (hiện trạng ban đầu): chọn file raster của CSDL (*_TK1.TIF);

+ Với Final State (hiện trạng cuối): chọn file raster từ phân loại ảnh (*_TK2.TIF);

+ Các kết quả của thống kê phát hiện biến động chọn là Area (có 3 tùy chọn Pixels (Số lượng pixel khác biệt) hoặc Percent (Số phần trăm khác biệt) hoặc Area (diện tích khác biệt));

+ Đặt tên file ảnh đánh dấu phân loại kết quả đầu ra (Output Classification Mask Images) với kích thước pixel là $6 \mathrm{~m}$;

+ Kết quả nhận được là ảnh đánh dấu phân loại kết quả đầu ra kèm theo số liệu thống kê phát hiện biến động của các nhóm đối tượng địa lý. Kết quả này giúp xác định nhanh mức độ biến động của CSDL đến thời điểm chụp ảnh, qua đó định hướng công tác Rà soát, cập nhật nội nghiệp đối tượng địa lý và chỉ dẫn bước Điều tra bổ sung ngoại nghiệp tiếp theo.

\section{Các kết quả}

+ Bảng biểu diện tích từng nhóm đối tượng biến động

+ Bản đồ hiển thị kết quả diện tích đối tượng biến động

\section{Thực nghiệm}

4.1. Biên tập, gộp các nhóm đối tuợng địa lý

Vì chỉ tập trung vào đối tượng dạng vùng (polygon) nên nhóm phủ bề mặt đảm bảo đủ các lớp đối tượng. Sau khi xác định gom các đối tượng theo 7 nhóm lớp, trên feature Tổng hợp tạo thêm trường "GomNhom” (kiểu dữ liệu text) gán từng đối tượng với tên theo các nhóm liệt kê trên trong bảng thuộc tính. (Xem hình 2)

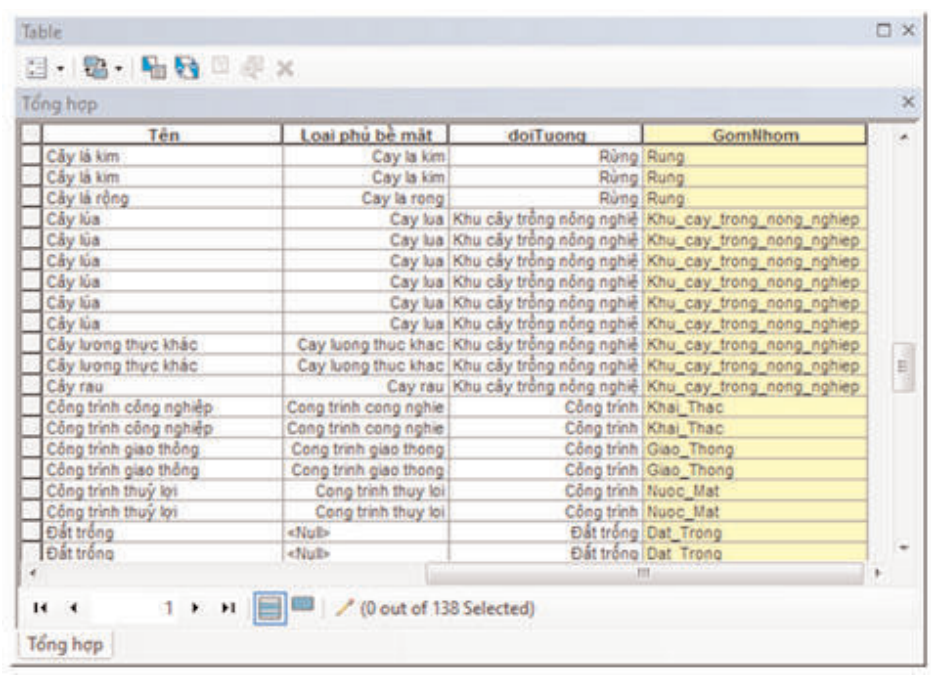

Hình 2: Bảng thuộc tính lớp Tổng hợp với trương GomNhom 
4.2. Chuyển đổi dũ liệu sang dạng raster

Sử dụng công cụ Feature to Raster trong phần mềm ArcGis

Kết quả sau khi thực hiện bước chuyển đổi:

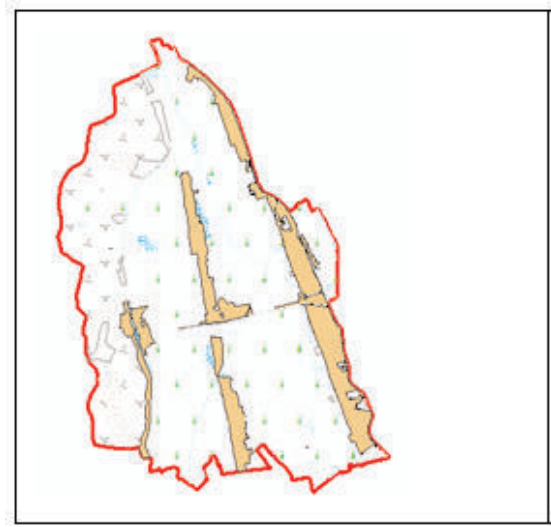

Hình 3: CSDL thể hiện bằng bộ ký hiệu 1: 10.000

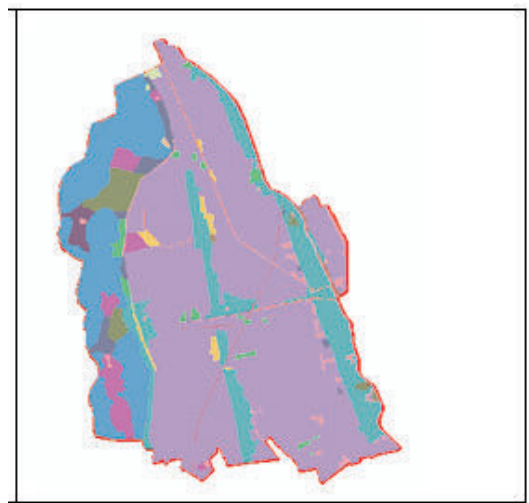

Hình 4: CSDL được chuyển sang dịnh dang Raster

\subsection{Anh vệ tinh SPOT 6,7 đa phổ}

Thu thập từ TKKT-DT "Bổ sung, cập nhật cơ sở dữ liệu nền địa lý các tỷ lệ khu vực 10 tỉnh: Thái Bình, Hà Nam, Nam Định, Ninh Bình, Thanh Hóa, Nghệ An, Hà Tĩnh, Quảng Bình, Quảng Trị, Thừa Thiên Huế" thuộc Cục Đo đạc, Bản đồ và Thông tin địa lý Việt Nam. (Xem hình 5)

4.4. Thống kê phát hiện biến động đối tương địa lý

Kết quả của quá trình là bảng biểu diện tích từng nhóm đôi tượng biên động trình bày tại bảng 2 dưới đây. (Xem bảng 2, hình 6)

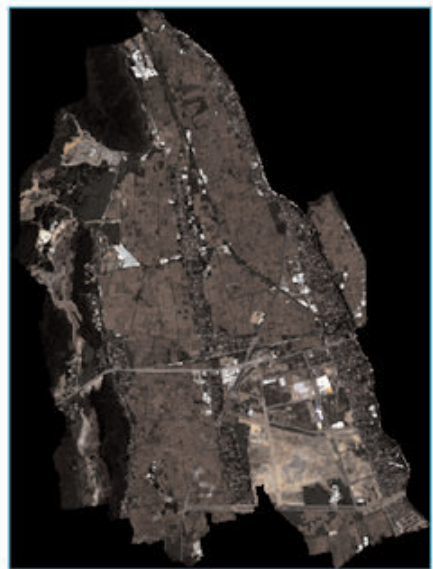

Hìn 5: Anh Spot cắt theo ranh giới khu vục nghiên cứu

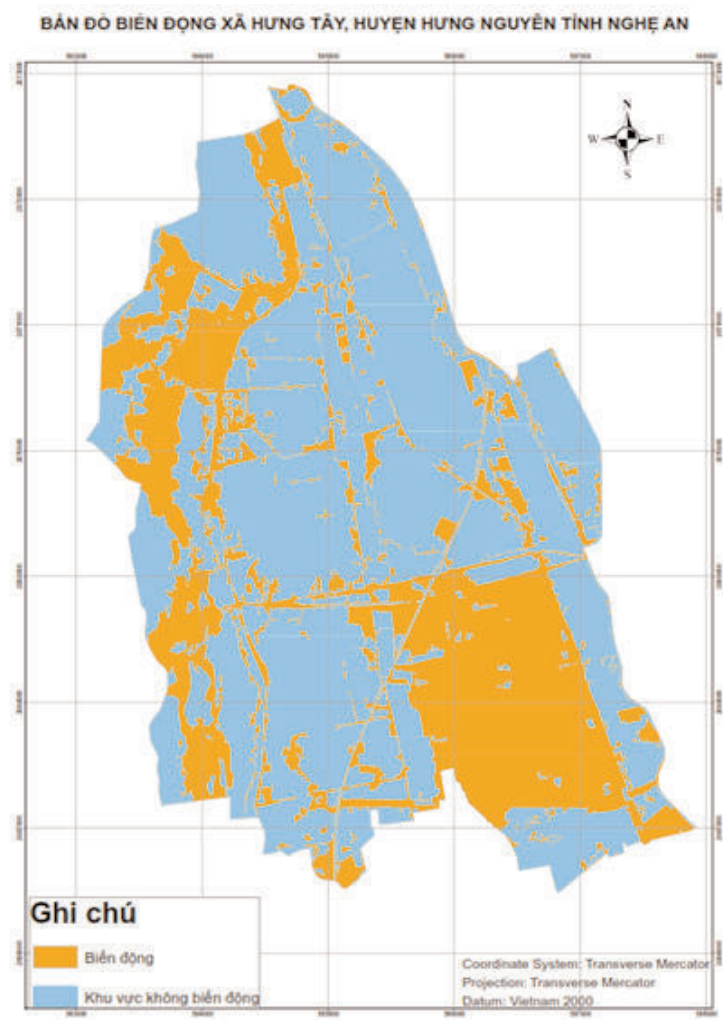

Hình 6: Bản đồ hiển thị kết quả diện tích đối tượng biến động 


\section{Bảng 2: Bảng ma trận biến động}

\begin{tabular}{|l|l|l|l|l|l|l|l|}
\hline $\begin{array}{r}\text { Thời kỳ 2 } \\
\text { (Từ ảnh Spot) }\end{array}$ & Dân cư & $\begin{array}{l}\text { Đất } \\
\text { trống } \\
\text { Thời kỳ 1 }\end{array}$ & $\begin{array}{l}\text { Giao } \\
\text { thông }\end{array}$ & $\begin{array}{l}\text { Khai thác, } \\
\text { công trình } \\
\text { công } \\
\text { nghiệp }\end{array}$ & $\begin{array}{l}\text { Khu cây } \\
\text { trồng } \\
\text { nông } \\
\text { nghiệp }\end{array}$ & $\begin{array}{l}\text { Nước } \\
\text { mặt }\end{array}$ & Rừng \\
\hline Dân cư & 231,75 & 1,5 & 10,98 & 0,51 & 4,71 & 0,69 & 5,41 \\
\hline Đất trống & 20,11 & 4,87 & 1,78 & 1,42 & 3,03 & 0,62 & 0,67 \\
\hline Giao thông & 0,74 & 0 & 5,67 & 0,02 & 0,05 & 0,15 & 0 \\
\hline $\begin{array}{l}\text { Khai thác, công trình } \\
\text { công nghiệp }\end{array}$ & 20,57 & 0,29 & 0,57 & 21,91 & 3,47 & 3,36 & 4,06 \\
\hline $\begin{array}{l}\text { Khu cây trồng nông } \\
\text { nghiệp }\end{array}$ & 184,33 & 47,44 & 41,01 & 126,46 & 697,67 & 19,64 & 10,48 \\
\hline Nước mặt & 19,52 & 0,31 & 1,56 & 1,91 & 2,4 & 32,7 & 0 \\
\hline Rừng & 22,91 & 8,7 & 0,49 & 65,53 & 6,34 & 2,09 & 199,2 \\
\hline
\end{tabular}

Nhìn vào số liệu trên bảng ma trận biến động (Bảng 2) thấy rằng giai đoạn 2009-2019 khu vực xã Hưng Tây, huyện Hưng Nguyên, tỉnh Nghệ An có sự biến động rất lớn về diện tích của các đối tượng địa lý. Diện tích biến động chiếm $(645,83 / 1839,6) * 100 \%=35 \%$ diện tích của toàn xã.

\section{Kết luận}

Việc sử dụng phương pháp chuyển đổi cơ sở dữ liệu định dạng vector sang định dạng raster so sánh cùng ảnh SPOT để đánh giá biến động góp phần bổ sung thêm các phương pháp đánh giá biến động.

Giải pháp sử dụng các nguồn tư liệu ảnh SPOT 6 năm 2019 sau khi xử lý phân loại và gom nhóm và CSDL nền địa lý quốc gia trước đó tiết kiệm chi phí, thời gian đảm bảo các yêu cầu kỹ thuật về xác định biến động bề mặt phục vụ lập thiết kế dự toán.

Quy trình phát hiện và đánh giá đưa ra được kết quả nhanh, chính xác đảm bảo phục vụ cho giai đoạn thiết kế kỹ thuật dự toán. $\bigcirc$

\section{Tài liệu tham khảo}

[1]. Thông tư số 21/2014/TT-BTNMT ngày 24 tháng 4 năm 2014 của Bộ trưởng Bộ Tài nguyên và Môi trường ban hành Quy định kỹ thuật về mô hình cấu trúc, nội dung cơ sở dữ liệu nền địa lý tỷ lệ 1:10.000.

[2]. Phan Kiều Diễm, Võ Quang Minh, Nguyễn Thị Hồng Điệp và Điệp Văn Đen, "Đánh giá tình hình sạt lở, bồi tụ khu vực ven biển tỉnh Cà Mau và Bạc Liêu từ 1995-2010 sử dụng viễn thám và công nghệ GIS", tạp chí khoa học trường đại học Cần Thơ năm 2013.

[3]. Atrium, SPOT6\& SPOT7 Imagery User Guide, SI/DC/13034-v1.0, July 2013.

[4]. JES, "Using of high resolution satellite images for updating large scale mapping in egypt",Assiut University, Faculty of Engineering, Vol. 42, No. 4, July 2014.

[5]. Karine Guerin, Marc Bernard, Thierry Rousselin, Jérôme Korona, Bénédicte Navaro, "Impact of Spot 6 and 7 Data in the Constitution and Update of Spatial Data Infrastructures over Africa"

[6]. Umut Gunes Sefercik, Murat Oruc and Mehmet Alkan, "Adaptation of High Resolution IKONOS Images to Google Earth for Zonguldak Test Field", Integrating Generations, FIG Working Week 2008, Stockholm, Sweden 14-19 June 2008. 0

(Xem tiếp trang 64) 